\title{
ENFOQUES HISTORIOGRÁFICOS Y REPRESENTACIONES SOCIALES EN LOS LIBROS DE TEXTO. UN ESTUDIO COMPARATIVO, ESPAÑA-FRANCIA-INGLATERRA*
}

\author{
Historiographical approaches and social representations in \\ textbooks. A comparative study, Spain-France-England
}

\section{Cosme J. Gómez Carrasco ${ }^{\varnothing}$ y Arthur Chapman ${ }^{\S}$}

Fecha de recepción: 06/09/2016 • Fecha de aceptación: 28/10/2016

Resumen. El presente artículo analiza los enfoques historiográficos y las representaciones sociales, nacionales, europeas y extra-europeas en los libros de texto de Educación Secundaria de España, Francia e Inglaterra. Para la muestra se han escogido 18 libros de texto de los dos primeros cursos de Educación Secundaria de los tres países. Se han seleccionado tres editoriales de gran presencia en las aulas en cada uno de los territorios (Anaya, Oxford y Vicens Vives para España; Belin, Bordas y Lelivrescolaire para Francia; y Collins, Heinemann o Hodder Education para Inglaterra). Los resultados muestran diferentes enfoques historiográficos en los manuales analizados, con un peso mayor del estructuralismo y del positivismo en el caso español; una clara influencia de las últimas generaciones de Annales en el caso francés; y un gran peso de la historia social y la historia desde abajo en el caso inglés. Además, los tres países presentan diferencias en las representaciones sociales. Los manuales franceses y españoles plantean el relato histórico dentro de un marco europeo del que se sienten partícipes. Sin embargo, los libros de texto ingleses presentan la construcción de la nación inglesa (sobre todo en los siglos de la Edad Media y Edad Moderna) desde una perspectiva muy anglocéntrica.

\footnotetext{
" Este artículo es resultado de los proyectos de investigación EDU2015-65621-C3-2-R «La evaluación de las competencias y el desarrollo de capacidades cognitivas sobre historia en Educación Secundaria Obligatoria»; EDU2014-51720-REDT RED 14 «Red de investigación en enseñanza de las ciencias sociales» $\mathrm{y}$ «Familia, desigualdad social y cambio generacional en la España centro-meridional, SS. XVI-XIX» (HAR2013-48901-C6-6-R) financiados por el Ministerio de Economía y Competitividad. ${ }^{\circ}$ Departamento de Didáctica de las Ciencias Matemáticas y Sociales. Facultad de Educación. Universidad de Murcia. Campus Universitario de Espinardo s/n. 30100, Murcia. España. cjgomez@um.es. $\S$ Department of Curriculum, Pedagogy and Assessment. UCL - Institute of Education. Gower Street. London WC1E 6BT. United Kingdom. arthur.chapman@ucl.ac.uk.
}

Cómo citar este artículo: Gómez Carrasco, Cosme J. y Chapman, Arthur. «Enfoques historiográficos y representaciones sociales en los libros de texto. Un estudio comparativo, España-Francia-Inglaterra ", Historia y Memoria de la Educación, 6 (2017): 319-361. 
Palabras clave: Libros de texto; Historiografía; Enseñanza de la historia; Representaciones sociales; Narrativa histórica.

Abstract. This paper analyzes the historiographical approaches and national, European and extra-European social representations in Secondary Education textbooks in Spain, France and England. We have chosen for the sample 18 textbooks used in the first two years of secondary education in the three countries, and. we have selected three large, renowned publishers within each country (Anaya, Oxford and Vicens Vives for Spain; Belin, Bordas and Lelivrescolaire for France, and Collins, Heinemann and Hodder Education for England). The results show different historiographical approaches in the textbooks analyzed, with a greater pre-eminence of structuralism and positivism in the Spanish case; a clear influence of the latest generations of Annales in the French case; and a greater importance given to social history and history-from-below in the English case. The three countries also differ in social representations; French and Spanish textbooks treat historical accounts within a European framework to which they feel they belong, while the English textbooks present the construction of the English nation (especially in the Middle Ages and the Modern Age) from a very Anglo-centric perspective.

Key words: Textbooks; Historiography; History education; Social representations; Historical narrative.

\section{INTRODUCCIÓN. EL LIBRO DE TEXTO COMO NARRATIVA HISTÓRICA Y SU PAPEL EN LA REPRESENTACIÓN DEL PASADO}

En su ensayo titulado La historia o la lectura del tiempo, ${ }^{1}$ Chartier realiza una reflexión sobre los debates en torno a la historia como relato, como narrativa, desde la década de 1970. Este autor destaca trabajos como los de Certeau, ${ }^{2}$ que pusieron el acento en la naturaleza discursiva de la historia, y cómo este debate sacudió los cimientos de la historia como disciplina. La dualidad entre narrativa y explicación ha sido cuestionada por Chartier, quien cree — como Certau- que la historia es narrativa, y que la explicación no es más que una forma de narrativa. El libro de texto es probablemente la narrativa histórica más leída por el conjunto de la sociedad, y quizás el único relato sobre historia que se utilice a lo largo de la vida junto con otros medios informales de conocimiento (mass-media, museos, otros centros de interés histórico, etc.).

\footnotetext{
${ }^{1}$ Roger Chartier, La historia o la lectura del tiempo (Madrid: Gedisa, 2007).

${ }^{2}$ Michel De Certeau, La escritura de la historia (México: Universidad Iberoamericana, 2010).
} 
Por ello tiene tanta importancia el análisis de ese relato, de esa narrativa, que ha creado tantas controversias por su uso (y abuso) en el ámbito educativo. $^{3}$

En España, a pesar de los continuos cambios legislativos en materia de educación en los últimos 25 años y las diferentes propuesta metodológicas en la enseñanza de la historia, el libro de texto sigue siendo el principal material didáctico utilizado por los docentes. ${ }^{4}$ No en todos los países de nuestro entorno existe la misma concepción y uso del libro de texto. Mientras que en algunos países el manual suele utilizarse en el aula para cubrir gran parte de los contenidos de la asignatura, así como para preparar al estudiantes para el examen, ${ }^{5}$ en otros lugares es sólo un recurso más tanto para el profesorado como para el estudiante. Es cierto que el libro de texto es un instrumento de enseñanza y aprendizaje que ha facilitado la labor del profesor y ha actuado como intermediario entre el estudiante y la materia. ${ }^{6}$ Valls ${ }^{7}$ realizó una propuesta que integra una serie de aspectos: historiográficos, comunicativos o epistemológicos, a la hora de establecer un análisis valorativo de los textos escolares de Historia. Esta propuesta complementa a la que ya Rüsen ${ }^{8}$ realizó, vinculando las funciones de la enseñanza de la historia y las propiedades de los manuales. Sin duda, y como indica Prats, ${ }^{9}$ el libro de texto ideal es el que facilita el aprendizaje de habilidades intelectuales, el dominio de técnicas y la construcción de conocimientos (metodología). En el caso

\footnotetext{
${ }^{3}$ Stuart Foster \& K. A. Crawford (eds.), What Shall We Tell the Children? International Perspectives on School History Textbooks (Greenwich, CT: Information Age Publishing, 2006).

${ }^{4}$ Nicolás Martínez, Rafael Valls y Francisco Pineda, «El uso del libro de texto de Historia de España en Bachillerato: diez años de estudio, 1993-2003 y dos reformas (LGE-LOGSE)», Didáctica de las ciencias experimentales y sociales, 23 (2009): 3-35.

${ }^{5}$ Cosme J. Gómez y Pedro Miralles, «Los contenidos de ciencias sociales y las capacidades cognitivas en los exámenes de tercer ciclo de Educación Primaria ¿Una evaluación en competencias?», Revista Complutense de Educación, 24 (2013): 91-121; Cosme J. Gómez y Pedro Miralles, «¿Pensar históricamente o memorizar el pasado? La evaluación de los contenidos históricos en la educación obligatoria en España», Revista de Estudios Sociales, 52, (2015): 52-68. Doi:10.7440/res52.2015.04.

${ }^{6}$ Joaquim Prats, «Criterios para la elección del libro de texto de historia», Íber. Didáctica de las Ciencias Sociales, Geografía e Historia, 70 (2012): 7-13.

${ }^{7}$ Rafael Valls, La enseñanza de la Historia y textos escolares (Buenos Aires: Zorzal, 2008).

${ }^{8}$ Jörn Russen, «El libro de texto ideal. Reflexiones en torno a los medios para guiar las clases de historia», Iber. Didáctica de las Ciencias Sociales, Geografía e Historia, 12 (1997): 79-90.

${ }^{9}$ Prats, «Criterio para la elección del libro de texto».
} 
de la historia, sin duda, el objetivo debe ser formar a los alumnos en el pensamiento histórico. ${ }^{10}$

La realidad es que los libros de texto cumplen una función transmisora del saber y del sentido de la realidad hegemónica por parte de las autoridades o del poder que generalmente no se cuestiona en sus páginas. ${ }^{11}$ El libro de texto, como indica Foster, ${ }^{12}$ es un poderoso artefacto cultural que contiene ideas y valores que los sectores influyentes de la sociedad esperan que los estudiantes aprendan y reproduzcan. Tradicionalmente la enseñanza de la historia ha sido considerada como el vehículo a través del cual las naciones buscan difundir y reforzar las narrativas que definen los conceptos de nación y la identidad nacional. ${ }^{13}$ Los libros de texto contienen muchos de los relatos que las naciones eligen para narrarla construcción de sus instituciones, su legitimación, sus relaciones con otras naciones, y la historia de su gente. ${ }^{14}$ Por tanto es clave analizar la construcción de ese relato en la línea que proponía Chartier, ${ }^{15}$ para comprender la intencionalidad que tienen las autoridades y otros agentes de influencia sobre la narrativa histórica que debe estar presente en el aula. Aunque también es necesario recordar, como indican muchos autores, ${ }^{16}$ que los contenidos mostrados por los libros de texto no son reproducidos literalmente por el docente, ni el alumnado los asimila sin procesarlos con su conocimiento anterior del tema. Esta interacción en-

\footnotetext{
${ }^{10}$ Cosme J. Gómez, Jorge Ortuño y Sebastián Molina, «Aprender a pensar históricamente. Retos para la historia en el siglo XXI», Tempo e Argumento, 6 (11), (2014): 1-25.; Jorge Sáiz, "Alfabetización histórica y competencias básicas en libros de texto de historia y en aprendizaje de los estudiantes», Didáctica de las Ciencias Experimentales y Sociales, 27 (2013): 43-66.

${ }^{11}$ Cosme J. Gómez, Ramón Cózar y Pedro Miralles, «La enseñanza de la historia y el análisis de libros de texto. Construcción de identidades y desarrollo de competencias», Ensayos. Revista de la Facultad de Educación de Albacete, 29 (1), (2014): 1-25.

${ }^{12}$ Stuart Foster, «Dominant Tradition in International Textbooks Research and Revision», Educational Inquiry, 2 (1), (2011): 5-20.

${ }^{13}$ Foster, «Dominant Tradition in International Textbooks».

${ }^{14}$ Michel W. Apple, Official Knowledge: Democratic Education in a Conservative Age (London: Routledge, 1993).

${ }^{15}$ Chartier, La historia o la lectura del tiempo.

${ }^{16}$ Entre ellos: M. W. Apple y L. K. Christian-Smith, «The Politics of theTextbook», en The Politics of the Textbook, eds. M. W. Apple y L. K. Christian-Smith (New York: Routledge, 1991), 1-21; R. J. Paxton, "A Deafening Silence: History Textbooks and the Students Who Read Them», Review of Educational Research, 69 (3), (1999): 315-339; D. Porat, «"It's Not Written Here, but This is What Happened»: Students' Cultural Comprehension of Textbook Narratives on the Israeli-Arab Conflict», American Educational Research Journal, 41 (2004): 963-996.
} 
tre el estudiante y la materia histórica muy influenciada por los medios de comunicación y otras fuentes informales de conocimiento.

Esta preocupación por el papel de los libros de texto en la enseñanza de la historia y su vinculación a la construcción de identidades colectivas ha producido una gran bibliografía en el ámbito internacional. Una muestra es el número monográfico de la revista International Journal of Historical Learning. Teaching and Research en 2003, el libro coordinado por Foster y Crawford, ${ }^{17}$ o el monográfico sobre este tema en la revista Educational Inquiry en 2011 (vol. 2, n. ${ }^{\circ}$ 1). Autores como Foster ${ }^{18}$ han hecho un interesante repaso de los enfoques teóricos y empíricos sobre el análisis de libros de texto, y trabajos como los de Nicholls ${ }^{19}$ o Pingel ${ }^{20}$ han presentado los principales métodos utilizados en las investigaciones sobre manuales. Aunque sin duda si hay que citar un centro de trabajo de referencia sobre este tema, tenemos que nombrar al Georg Eckert Institute for International Textbook Research en Braunschweig (Alemania). Este centro es uno de los principales focos de investigación sobre libros de texto en el ámbito mundial con una gran cantidad de proyectos de investigación que abarcan un notable número de temas. El Instituto Georg Eckert lleva a cabo una investigación multidisciplinar sobre los libros de texto, principalmente para la enseñanza de la historia y los estudios sociales y culturales. El reciente trabajo de Elmersjö ${ }^{21}$ ha puesto énfasis en uno de los proyectos internacionales que ha llevado a cabo el Instituto Georg Eckert en colaboración con las universidades suecas de Umeå y Karlstad. Este proyecto ha analizado los cambios en la enseñanza de la historia en Europa a través de los manuales a lo largo del siglo xx y la primera década del siglo XXI.

\footnotetext{
${ }^{17}$ Foster y Crawford, What Shall We Tell the Children?

${ }^{18}$ Foster, «Dominant Tradition in International Textbooks»; Stuart Foster, «Re-thinking History Textbooks in a Globalized World», en History Education and the Construction of National Identities, eds. M. Carretero; M. Asensio y M. ${ }^{\text {a }}$ Rodríguez-Moneo (Charlotte: IAP Publishing, 2012), 49-62.

${ }^{19}$ J. Nicholls, «Methods in School Textbooks Research», International Journal of Historical Learning. Teaching and Research, 3 (1), (2003): 11-26.

${ }^{20} \mathrm{~F}$. Pingel, UNESCO guidebook on textbook research and textbook revision (Braunschweig: GEI/ UNESCO, 2010).

${ }^{21} \mathrm{H}$. A. Elmersjö, «History beyond borders: Peace education, history textbooks revision, and the internacionalization of history teaching in the twentieth century», Historical Encounters. A journal of historical consciousness, historical cultures, and history education, 1 (1), (2014): 62-74.
} 
En Europa, por tanto, el análisis de libros de texto es una línea de investigación fundamental para comprender las tensiones en la enseñanza de la historia, su problemática y relaciones con el poder, los currículos, la construcción de identidades y el contexto histórico, social y cultural. ${ }^{22}$ La mayoría de estos trabajos han profundizado sobre la construcción del concepto de Europa, la presencia de los grandes traumas sociales y políticos (Primera y Segunda Guerra Mundial, el fascismo, el nazismo, etc.), la comparativa entre las diferentes formas de enfocar la nación, y los cambios en la enseñanza de la historia que se visualizan a través de los manuales. Una trayectoria parecida sobre esta línea de investigación se ha desarrollado en EE. UU., como muestran los trabajos de Foster ${ }^{23} \mathrm{o}$ Giordano. ${ }^{24}$ En el caso de Estados Unidos las investigaciones han puesto énfasis en la construcción de la nación y en los valores que se transmiten en los libros de texto de historia en torno a las grandes figuras nacionales como Lincoln, Luther King o Kennedy, sus hazañas y virtudes. La imagen del otro, la creación de identidades, imágenes y estereotipos, así como las diferentes visiones sobre acontecimientos de relevancia nacional, son temáticas que también son analizadas en otros territorios como Japón, ${ }^{25}$

\footnotetext{
${ }^{22}$ Sin ánimos de ser exhaustivos, pero sí dejando constancia de la gran cantidad de textos que han abordado estas temáticas, ponemos como ejemplo: P. Aubin, «La pénétration des manuels scolaires de France au Québec. Un cas-type: Les frères des Écoles chrétiennes, XIXe-Xxe siècles», Histoire de l'Edutation, 85 (2000): 3-24; M. C. Baquès, «L'évolution des manuels d'histoire du lycée. Des années 1960 aux manuels actuels», Histoire de l'Education, 114 (2007): 121-149; L. Cajani, «Italian history textbooks on the brink of the twenty-first century», en School history textbooks across cultures: International debates and perspectives, eds. J. Nicholls (Oxford: Symposium books, 2006), 27-41; M. Estivalèzes, «Teaching About Islam in the History Curriculum and in Textbooks in France», Journal of Educational Media, Memory, and Society, 7 (3), (2011): 45-60; F. Pingel, The European home: Representations of 20th century Europe in history textbooks (Strasbourg: Council of Europe, 2000); G. Stöber, «From textbook comparison to common textbooks? Changing patterns in international textbook revision", en History education and post-conflict reconciliation: Reconsidering joint textbook projects, eds. K. V. Korostelina y S. Lässig (New York: Routledge, 2013), 26-51; A. Wilschut, «History at themercy of politicians and ideologies: Germany, England, and the Netherlands in the 19th and 20th centuries», Journal of Curriculum Studies, 42 (5), (2011): 693-723; D. Zachos y A. Michailidou " "Others" in Textbooks: The Case of Greek Sixth Grade's History Textbook», Theory in Action, 7 (3): 1-25. DOI:10.3798/tia.1937-0237.14016.

${ }^{23}$ Stuart Foster, «The struggle for American identity: Treatment of ethnic groups in United States history textbooks», History of Education, 28 (1999): 251-279.

${ }^{24}$ G. Giordano, Twentieth-century textbook wars: A history of advocacy and opposition (New York: Peter Lang, 2003).

${ }^{25}$ K. Fukuoka, «School History Textbooks and Historical Memories in Japan: A Study of Reception», International Journal of Politics, Culture and History, 24 (2011): 83-103.
} 
Israel, ${ }^{26}$ Canadá ${ }^{27}$ o Australia. ${ }^{28}$ De igual forma, en Latinoamérica las investigaciones sobre los manuales escolares de historia han incidido en el mensaje identitario que transmiten a través de temas clave como los procesos de independencia o la llegada de Colón a América. ${ }^{29}$ De hecho, estos últimos autores recuerdan algunos de los debates sobre la enseñanza de la historia que han surgido en territorio americano (tanto en EE. UU. como en Latinoamérica), y que están íntimamente vinculados con los libros de texto, las relaciones entre el poder, la escuela y la enseñanza de la historia, así como la construcción de identidades sociales y culturales.

En España los trabajos sobre los libros de texto constituyen una línea de investigación muy fructífera en los últimos veinte años. ${ }^{30} \mathrm{El}$ principal autor español sobre este tema, y que ha sido el pionero en abordar los manuales de una forma rigurosa y sistemática desde la didáctica de las ciencias sociales ha sido Rafael Valls. En los trabajos citados anteriormente el autor ha incidido en el uso y selección de las imágenes, en el

\footnotetext{
${ }^{26}$ A. Kizel, «The presentation of Germany in Israelí History Textbooks between 1948-2014», Journal of Educational Media, Memory and Society, 7 (1), (2015): 94-115.

${ }^{27}$ Penney Clark, ««A Nice Little Wife to Make Thing Pleasant»: Portrayal of Women in Canadian History textbooks approved in British Columbia», McGill Journal of Education, 40 (2), (2005): 241-265.

${ }^{28}$ Robert J. Parkes y Heather Sharp, «Nietzschean perspectives on representations of national history in Australian school textbooks: What should we do with Gallipoli?», Ensayos. Revista de la Facultad de Educación de Albacete, 29 (1), (2014): 159-181.

${ }^{29}$ Mario Carretero, Alberto Rosa y M. ${ }^{a}$ Fernanda González, «Enseñar historia en tiempos de memoria», en La enseñanza de la historia y memoria colectiva, eds. M. Carretero, A. Rosa y M. ${ }^{a}$ F. González (Buenos Aires: Editorial Paidós, 2006), 11-36.

${ }^{30}$ Cosme J. Gómez, «Pensamiento histórico y contenidos disciplinares en los libros de texto. Un análisis exploratorio de la Edad Moderna en 2. ${ }^{\circ}$ de la ESO», Ensayos. Revista de la Facultad de Educación de Albacete, 29 (1), (2014): 131-158; Gómez, Cózar y Miralles, «La enseñanza de la historia y el análisis de libros de texto»; Nicolás Martínez, «El uso de los manuales escolares de historia de España. Análisis de resultados desde la propuesta de Shulman", Íber. Didáctica de las Ciencias Sociales, Geografía e Historia, 70 (2012): 48-58; Jorge Sáiz, "Actividades de libros de texto de Historia, competencias básicas y destrezas cognitivas, una difícil relación: análisis de manuales de $1 .^{\circ}$ y $2 .^{\circ}$ de ESO», Revista Didáctica de las Ciencias Experimentales y Sociales, 25 (2011): 37-64; Jorge Sáiz, «El tratamiento de las competencias básicas en los actuales libros de texto de historia en secundaria. Limitaciones y propuestas de mejora", Íber. Didáctica de las Ciencias Sociales, Geografía e Historia, 74 (2013): 52-61; Rafael Valls, «Las imágenes en los manuales escolares españoles de Historia, ¿ilustraciones o documentos?», Íber. Didáctica de las Ciencias Sociales, Geografía e Historia, 4 (1995): 105-119; Rafael Valls, «Sobre la elección y usos de las imágenes de los manuales escolares de historia: un ejemplo español (1900-1998)», Clío \& asociados. La historia enseñada, 4 (1999): 77-100; Rafael Valls, «Los estudios sobre manuales escolares de historia y sus nuevas perspectivas», Didáctica de las Ciencias Experimentales y Sociales, 15 (2001): 23-36; Rafael Valls, «La Guerra Civil española y la dictadura franquista: las dificultades del tratamiento escolar de un tema potencialmente conflictivo", Enseñanza de las Ciencias Sociales. Revista de investigación, 6 (2007): 61-73.
} 
tratamiento de temas históricos relevantes como el Islam o la Guerra Civil española, y en síntesis sobre las investigaciones llevadas a cabo sobre libros de texto y propuestas de análisis concretas. A partir de estos estudios de Valls se han ido desarrollando diversas temáticas en el análisis de los manuales y su relación con la enseñanza de la historia tanto en Educación Primaria como en Secundaria. El análisis de los contenidos seleccionados por los manuales todavía tienen una gran presencia. ${ }^{31} \mathrm{Sin}$ embargo las investigaciones se han ampliado hacia otros ámbitos de trabajo como el tiempo histórico, el análisis de las actividades y su relación con las competencias. ${ }^{32}$

En este contexto de producción bibliográfica, este estudio quiere aportar una visión comparativa de las representaciones sociales y los enfoques historiográficos en tres territorios clave de la Europa Occidental: Inglaterra, Francia y España. Estos tres territorios han tenido una gran presencia en otros continentes, y su influencia lingüística y cultural a nivel mundial es muy notable. Además, son territorios receptores de inmigración, por lo que las aulas suelen tener un aspecto bastante multicultural. Ante estas circunstancias la finalidad ha sido analizar qué visión historiográfica presentan los manuales, y qué representaciones sociales, nacionales y no nacionales son hegemónicas en sus páginas.

\section{METODOLOGÍA}

\section{Objetivos}

El objetivo principal de este trabajo es analizar los enfoques historiográficos y las representaciones sociales de los contenidos propuestos en los libros de texto de historia en Educación Secundaria desde una pers-

\footnotetext{
${ }^{31}$ José María Cuenca e Isabel López, «La enseñanza del patrimonio en los libros de texto de Ciencias Sociales, Geografía e Historia para ESO», Cultura y Educación, 26 (1), (2014): 1-43; Cosme J. Gómez y Ana María López, «Las imágenes de los libros de texto y su función en la enseñanza de la historia. Diseño de un instrumento de análisis», Enseñanza de las Ciencias Sociales, Revista de Investigación, 13 (2014): 17-29; R. López Facal, «Nacionalismos y europeísmos en los libros de texto: identificación e identidad nacional», Clío \& asociados: la historia enseñada, 14 (2010): 9-33; Jorge Sáiz, «La Península Ibérica medieval y las identidades en los actuales libros de texto de historia de $2 .{ }^{\circ}$ ESO", Íber. Didáctica de las Ciencias Sociales, Geografía e Historia, 70 (2012): 67-77.

${ }^{32}$ A. Blanco, «La representación del tiempo histórico en los libros de texto de primero y segundo de la Enseñanza Secundaria Obligatoria», Enseñanza de las Ciencias Sociales. Revista de investigación, 7, (2008): 77-88; Gómez, «Pensamiento histórico y contenidos disciplinares»; Sáiz, «El tratamiento de las competencias básicas».
} 
pectiva comparativa (España-Francia-Inglaterra). Para conseguir este objetivo general se han propuesto dos objetivos concretos:

- Analizar la tipología de conocimientos históricos que se proponen en los libros de texto, diferenciando entre diversos enfoques historiográficos y de contenidos.

- Estudiar las representacional sociales, analizando la presencia de temas nacionales, europeos y extra-europeos propuestos en los libros de texto.

\section{Muestra}

La muestra la componen 18 libros de texto utilizados en los dos primeros cursos de Educación Secundaria en España, Francia e Inglaterra. En cada país se ha analizado seis libros, tres editoriales por curso. Las editoriales analizadas han sido Anaya (2015 para 1. ${ }^{\circ}$ de la ESO y 2013 para 2. ${ }^{\circ}$ de la ESO), Oxford (2015 para $1 .^{\circ}$ de la ESO y 2013 para $2 .^{\circ}$ de la ESO) y Vicens Vives (2015 para $1 .^{\circ}$ de la ESO y 2013 para $2 .^{\circ}$ de la ESO); Belín (2011), Bordas (2011) y Lelivrescolaire (2011) para $5 .^{\circ}$ y $4 .^{\circ}$ de Collège en Francia; y Collins (2015), Heinemann (2011), y Hodder Education (2008) para $7 .^{\circ}$ y $8 .^{\circ}$ curso de Inglaterra.

\section{Método y categorización de datos}

Debido a la naturaleza de esta investigación y a los objetivos propuestos, se adoptó un diseño metodológico que combinara diferentes técnicas y estrategias, y que se sitúa dentro de los denominados métodos no experimentales: las variables independientes ya han ocurrido o no son manipulables. ${ }^{33}$ La intención es tratar de conocer una realidad: los enfoques historiográficos y las representaciones sociales nacionales y no nacionales en los libros de texto desde una perspectiva comparativa. El análisis de los datos se ha realizado combinando un enfoque cuantitativo

\footnotetext{
${ }^{33}$ F. N. Kerlinger, Investigación del comportamiento. Métodos de investigación en ciencias sociales, (México: McGraw-Hill, 2002).
} 
y cualitativo. Las principales investigaciones sobre la educación histórica han insistido también en esta complementariedad de enfoques. ${ }^{34}$

Las técnicas de análisis cuantitativo se aplicaron en este trabajo a través de frecuencias, medias y porcentajes de las categorías que lo permitían (tabla 1). Las técnicas de análisis cualitativo se han realizado a través de un análisis textual, principalmente sobre la construcción de esas representaciones sociales sobre temáticas nacionales y no nacionales. El análisis cualitativo es un proceso que consiste en «dar sentido» a la información textual. Las investigaciones más recientes e innovadoras en didáctica y, en general, en ciencias sociales recurren habitualmente a esta metodología. Es difícil en muchos casos acercarse a la realidad sin la utilización de métodos cualitativos, puesto que cerrar las posibilidades de respuesta nos puede llevar a perder información que facilite la comprensión del fenómeno estudiado. ${ }^{35}$

Tabla 1. Categorización de datos sobre enfoques historiográficos

\begin{tabular}{|l|l|l|}
\hline \multicolumn{1}{|c|}{ CATEGORÍA } & \multicolumn{1}{|c|}{ SIGNIFICADO } & \multicolumn{1}{c|}{ EJEMPLO } \\
\hline Personajes & $\begin{array}{l}\text { Biografías de personajes y estudios } \\
\text { de caso de esos personajes }\end{array}$ & $\begin{array}{l}\text { Estudio de la vida de Elisabeth en } \\
\text { Inglaterra o de Voltaire en los libros } \\
\text { franceses, etc }\end{array}$ \\
\hline $\begin{array}{l}\text { Historia política } \\
\text { e institucional }\end{array}$ & $\begin{array}{l}\text { Páginas dedicadas a guerras, } \\
\text { batallas, política interior, política } \\
\text { exterior y divisiones institucionales }\end{array}$ & $\begin{array}{l}\text { Política exterior de los Reyes } \\
\text { Católicos, Guerras de Religión, } \\
\text { Revolución Francesa, la Guerra de } \\
\text { los Cien Años, etc. }\end{array}$ \\
\hline $\begin{array}{l}\text { Cultura, religión } \\
\text { y pensamiento }\end{array}$ & $\begin{array}{l}\text { Temáticas sobre pensamiento, } \\
\text { ciencia, mentalidades, cultura, y } \\
\text { religión. }\end{array}$ & $\begin{array}{l}\text { Revolución Científica, Humanismo, } \\
\text { Contrarreforma, etc. }\end{array}$ \\
\hline
\end{tabular}

\footnotetext{
${ }^{34}$ Rosalyn Ashby, «Developing a concept of historical evidence: Students' ideas about testing singular factual claims», International Journal of Historical Learning, Teaching and Research, 4 (2), (2004): 44-55; Isabel Barca, ««Till new facts are discovered»: Students'ideas about objectivity in history», en International review of history education, Vol. 4: Understanding history: Recent research in history education, eds. R. Ashby, P. Gordon y P. Lee (New York: Routledge Falmer, 2005), 68-82; Keith C. Barton, «Applied research: Educational research as a way of seeing», en The professional teaching of history: UK and Dutch perspectives, eds. A. McCully, G. Mills, C. van Boxtel (Coleraine, Northern Ireland: History Teacher Education Network, 2012), 1-15; Joaquim Prats, «Hacia una definición de la investigación en Didáctica de las Ciencias Sociales», Enseñanza de las Ciencias Sociales. Revista de investigación, 1, (2002): 81-89.

${ }^{35}$ Isabel Barca, «La evaluación de los aprendizajes en historia», en La evaluación y el proceso de enseñanza y aprendizaje de las ciencias sociales, eds. P. Miralles, S. Molina y A. Santisteban (Murcia: AUPDCS, 2011), 107-120.
} 


\begin{tabular}{|l|l|l|}
\hline \multicolumn{1}{|c|}{ CATEGORÍA } & \multicolumn{1}{|c|}{ SIGNIFICADO } & \multicolumn{1}{c|}{ EJEMPLO } \\
\hline Historia del arte & $\begin{array}{l}\text { Páginas sobre historia del arte, } \\
\text { pintura, escultura, arquitectura y } \\
\text { figurismo. }\end{array}$ & $\begin{array}{l}\text { Arte Gótico, Arte Románico, } \\
\text { características y autores de cada } \\
\text { estilo artístico, etc. }\end{array}$ \\
\hline $\begin{array}{l}\text { Historia social y yó } \\
\text { económica } \\
\text { estructural }\end{array}$ & $\begin{array}{l}\text { Temáticas sobre sociedad y economía } \\
\text { abordados desde una perspectiva } \\
\text { estructural. }\end{array}$ & $\begin{array}{l}\text { División de la sociedad, análisis } \\
\text { estructural de los procesos de } \\
\text { crecimiento y crisis económica, etc. }\end{array}$ \\
\hline $\begin{array}{l}\text { Vida cotidiana, } \\
\text { género, conflicto } \\
\text { e historia desde } \\
\text { abajo }\end{array}$ & $\begin{array}{l}\text { Temáticas sobre sociedad desde un } \\
\text { enfoque de historia desde abajo, } \\
\text { microhistoria, historia de las } \\
\text { mujeres, historia de la vida } \\
\text { cotidiana, etc. }\end{array}$ & $\begin{array}{l}\text { Leyes de pobres, estudios de caso } \\
\text { sobre el campesinado en libros } \\
\text { ingleses, etc. }\end{array}$ \\
\hline
\end{tabular}

\section{ANÁLISIS Y DISCUSIÓN DE RESULTADOS}

\section{Unas trayectorias historiográficas diferentes}

Gráfico 1. Temas históricos en los libros de texto de España, Francia e Inglaterra (primer curso de Educación Secundaria)

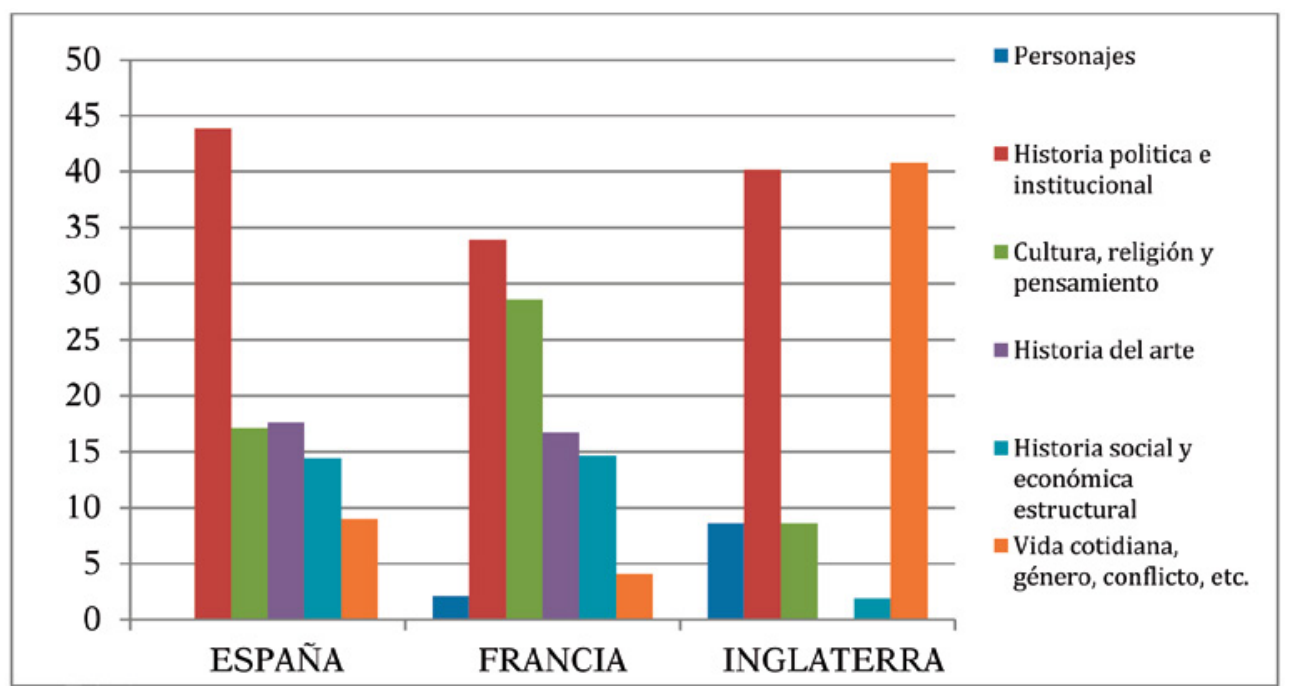


Gráfico 2. Temas históricos en los libros de texto de España, Francia e Inglaterra (segundo curso de Educación Secundaria)

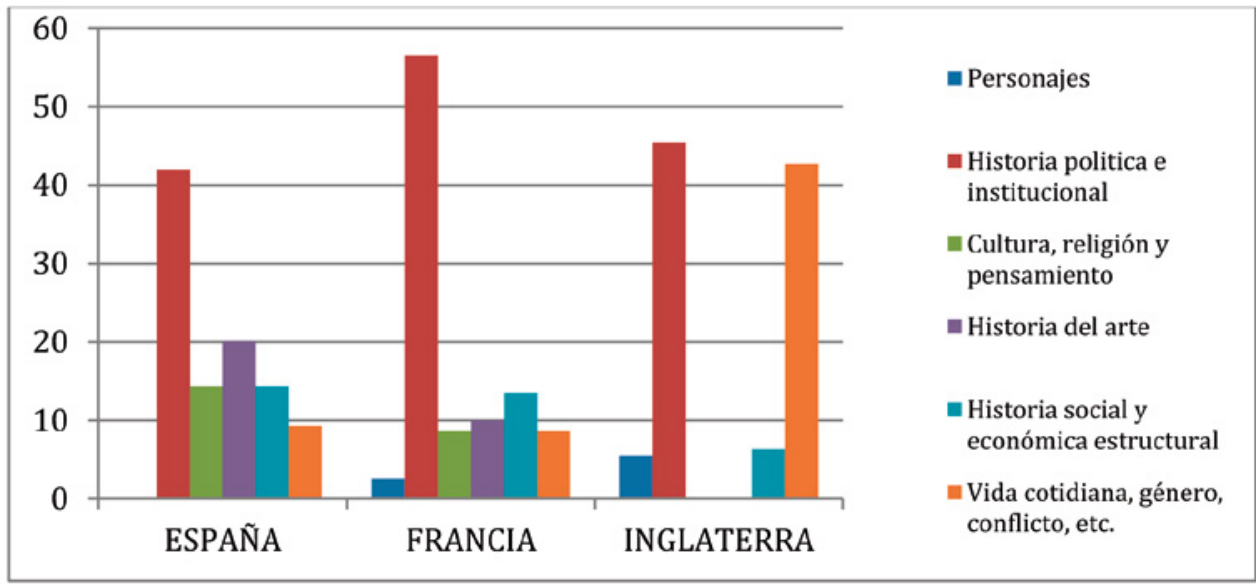

Gráfico 3. Temas históricos en los libros de texto de España, Francia e Inglaterra (Edad Media y Edad Moderna)

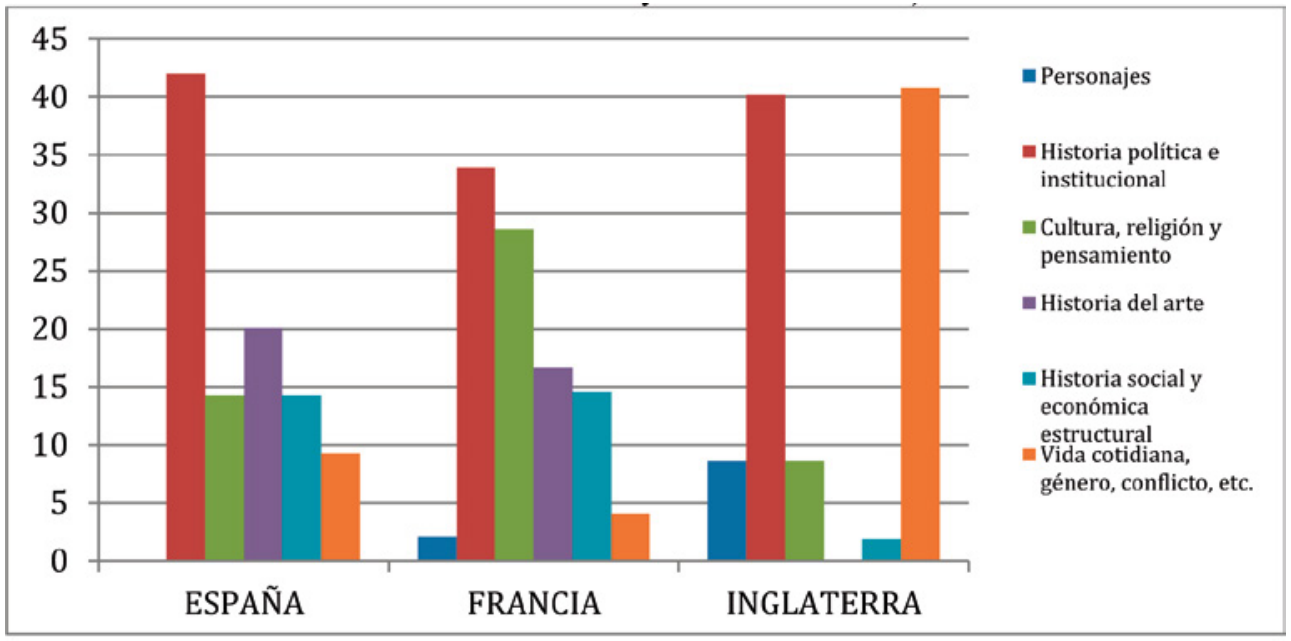

Los resultados muestran cómo los libros de texto de España, Francia e Inglaterra presentan los contenidos de historia desde distintas perspectivas historiográficas (gráficos 1, 2 y 3). La historia política e institucional tiene un peso similar en los manuales de los tres países: entre el 40-45\% de las páginas. En España y Francia el resto se divide entre la historia 
cultural y del pensamiento (más presente en Francia), la historia del arte (más presente en España), la historia social y económica estructural (similar en ambos países) y la historia de la vida cotidiana (ligeramente superior en España). Los manuales ingleses tienen un modelo diferente. La historia de la vida cotidiana, el género, el conflicto, etc. ocupan tantas páginas como la historia institucional y política. El resto del manual (apenas un 15\%) es historia cultural y del pensamiento.

En el caso de España los contenidos son presentados desde una combinación de positivismo clásico (modelo rankeano con una secuencia de datos y fechas desde una perspectiva cronológica) y una propuesta estructural que proviene en gran parte de la escuela historiográfica de Annales. El modelo rankeano es perceptible principalmente en dos rasgos. En primer lugar, por la ordenación cronológica de los temas en un sentido bastante estricto. Por ejemplo, el manual de Vicens Vives de 2. ${ }^{\circ}$ de la ESO para la Edad Moderna va avanzando desde el nacimiento del Estado Moderno, los descubrimientos geográficos, la monarquía autoritaria de los Reyes Católicos, el Imperio de los Austrias y el siglo del Barroco. Una secuenciación bastante clara siguiendo el esquema desde finales del siglo XV hasta el siglo XVII. En segundo lugar, por la preeminencia de la historia política. No sólo en número de páginas (el porcentaje es similar en los tres países), sino en la forma de organizar los temas. Las coyunturas políticas (el califato, los reinos de Taifas, los reinos cristianos, el Imperio de los Austrias, etc.) son el vehículo estructurante de la narrativa histórica transmitida en el libro de texto. En esas temáticas se sigue un orden cronológico de etapas, batallas, reinados, etc. A partir de esas coyunturas políticas el discurso va entrando en otros temas económicos, sociales, culturales y artísticos, ya desde una perspectiva más estructural.

Precisamente la herencia de Annales se percibe en esa parcelación que los manuales realizan entre historia política, historia social, historia económica, pensamiento, cultura y arte, en busca del ideal de historia total. ${ }^{36}$ Siguiendo esta influencia, los manuales plantean la historia desde una perspectiva esencialmente estructuralista. Aunque existe una preeminencia de la historia política e institucional en las páginas de los libros de texto, la influencia de Annales ha impulsado desde 1990 un mayor

\footnotetext{
${ }^{36}$ A. Berr, A. En marge de l'histoire universelle (París: Albin Michel, 1953); E. Le Roy, Montaillou, village occitan de 1294 à 1324 (París: Gallimard, 1975).
} 
equilibrio con respecto a otras temáticas sociales, económicas, culturales y artísticas. ${ }^{37}$ Muchos de los temas se identifican directamente con los siglos que se van a desarrollar (La Europa del Renacimiento — siglo XVI-, la Europa del Barroco — siglo XVII-...), e internamente estos temas se dividen en diferentes apartados que desarrollan temáticas como la conceptualización del poder; la trayectoria de esas instituciones de poder (política interior, política exterior, principales batallas y guerras, así como personalidades políticas relevantes); la división estructural de la sociedad (en estamentos o clases, con una breve descripción de cada una); la explicación de crecimiento o recesión de la economía; rasgos culturales; y características artísticas. Los temas de vida cotidiana han comenzado a incorporarse en los manuales en los últimos años, aunque con una gran carga estereotipada, y todavía desde una perspectiva estructuralista.

Es cierto que se aprecia una notable mejora en la manera de mostrar los contenidos en los manuales españoles desde finales de la década de 1990. Las actividades que se han introducido en los últimos años han ido incrementando su complejidad, intentando huir del discurso lineal dominante. Como indica Valls, ${ }^{38}$ estos cambios son producto de una mayor preocupación didáctica por parte de las editoriales, lo que algunos denominan como pedagogización de los contenidos. Sin embargo existe una gran confusión entre competencias clave - generalistas, transversales - y habilidades históricas - uso de fuentes, trabajo con causas y consecuencias, el cambio y la continuidad, o la relevancia histórica-. ${ }^{39}$ Así, en los manuales actuales se combinan actividades que buscan la memorización de los contenidos expuestos en el texto con ejercicios que quieren desarrollar otro tipo de habilidades: sintetizar, esquematizar, resumir, buscar información y —minoritariamente- reflexionar. Este tipo de habilidades tienen más relación con las competencias transversales propuesta por la LOE y la LOMCE que con el método del historiador. Una excepción es el libro de Vicens Vives editado en 2015 (para 1. ${ }^{\circ}$ de

\footnotetext{
${ }^{37}$ Pedro Miralles, «Las tendencias historiográficas recientes y la enseñanza de la Historia en Bachillerato», Revista de historiografía, 2, (2005): 158-166; Javier Paniagua, «Dejad a los políticos en la cuneta. La historia social busca su propio espacio», Íber. Didáctica de las Ciencias Sociales, Geografía e Historia, 12, (1997): 25-36.

${ }^{38}$ Valls, «Los estudios sobre manuales escolares de historia».

${ }^{39}$ Gómez y Miralles, «¿Pensar históricamente o memorizar el pasado?»; Peter Seixas y Tom Morton, The Big Six Concept of Historical Thinking (Toronto: Nelson, 2013); Sáiz, «Alfabetización histórica y competencias básicas».
} 
la ESO, adaptado a la nueva normativa LOMCE), en el que sí aparecen estudios de caso ficticios y un taller de historia que muestran otra forma de mostrar los conocimientos históricos.

La herencia de Annales es más visible en los libros de texto franceses y la influencia positivista es mucho más reducida. Es cierto que en los manuales franceses se refleja una visión más amplia y rica de la escuela historiográfica de Annales, con rasgos sobre la vida cotidiana, cultura y pensamiento desde otra perspectiva más inductiva e interdisciplinar. Aquí se puede observar la influencia de la llamada «tercera generación de Annales», caracterizada por los estudios sobre historia de las mentalidades, como los trabajos de George Duby o Pierre Nora. Hay muchos ejemplos de esta cuestión. Así, el manual de Lelivrescolaire de $4 .^{\circ}$ tiene un dossier dedicado al nacimiento y afirmación de la intimidad en el siglo XVIII, centrado en los cambios para la mujer en cuanto a la actividad íntima, los instrumentos utilizados en el aseo diario, la lectura, etc. En el tema sobre la Europa de las Luces los tres manuales analizados le dedican un número importante de páginas a personajes como Diderot o Voltaire, a las ideas revolucionarias, el papel de la Enciclopedia, la difusión y circulación de nuevas ideas en Europa, etc. Existe un dossier en el

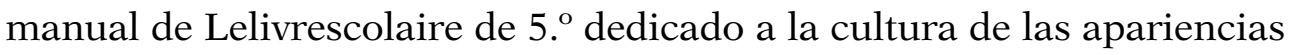
para analizar las imágenes del Barroco y la naturaleza del poder. Este último dossier es una buena muestra de esta propuesta historiográfica, donde la historia cultural se funde con la historia política, la historia social y la historia del arte. Así, otros temas como la transformación de la imagen del artista en el Renacimiento [De l'artisan à l'artiste exceptionnel (xve-xvie siècles)], o el dossier dedicado a la temprana preocupación por el patrimonio en el siglo XIX inciden en esas temáticas culturales. Es en estos últimos ejemplos donde la influencia de historiadores como Le Goff ${ }^{40}$ o Chartier, ${ }^{41}$ en su obras de madurez, es bastante evidente y se percibe ese giro crítico de la cuarta generación de esta escuela historiográfica de Annales.

\footnotetext{
${ }^{40}$ Jacques Le Goff, Marchands et banquiers du Moyen Âge. Que sais-je? (Paris: PUF, 2001); Jacques Le Goff, Roger Chartier, y Jacques Revel, La nouvelle histoire (París: PUF, 1978).

${ }^{41}$ Roger Chartier, Cultural History: Between Practices and Representations (Cornell: Cornell University Press, 1993).
} 
Además, en los manuales franceses hay estudios de caso, análisis de fuentes primarias, actividades que trabajan con textos de historiadores e imágenes. Una cuestión que les acerca más a la auténtica filosofía de Annales sobre la necesidad de que los libros de historia transmitiera los procedimientos a través de los que se ha conseguido el conocimiento (el método del historiador), como indicó en su día Marc Bloch. ${ }^{42}$ Hay muchos temas que comparten los manuales de España y Francia: el papel de la Iglesia Católica y el Islam en la época medieval; las comunidades rurales en la Edad Media; el feudalismo como sistema político, económico y social; las ciudades medievales; la construcción de las monarquías autoritarias desde finales de la Edad Media; el Humanismo, Renacimiento y Contrarreforma; o la monarquía absoluta. El tratamiento de estos temas es muy similar, con mayores actividades inductivas en el caso francés. Sin embargo. es en los temas transversales e interdisciplinares como el dossier sobre las ciudades portuarias del siglo XVIII, el esclavismo, la Europa de las Luces, etc. donde son más visibles estas diferencias de enfoque historiográfico. Mientras que en los manuales franceses se adentran en estudios de caso, e interrogan diferentes fuentes icónicas y textuales para hacer reflexionar al alumnado sobre estas temáticas, en el caso español se hace más hincapié en temas estructurales y en la trayectoria de las instituciones de poder.

Los contenidos históricos propuestos por los libros de texto ingleses tienen unas influencias historiográficas muy distintas. Para comenzar, no existen temas sobre historia del arte, mientras que estos temas ocupan un espacio muy amplio en los libros de texto españoles y franceses. Muy parecido es el caso de temas culturales. Mientras que en Francia y en España temas como el Humanismo, la Contrarreforma, la mentalidad barroca, la revolución científica, etc. tienen un peso importante, en Inglaterra apenas aparecen. Igualmente, la historia social y económica de tipo estructural no tiene gran presencia en los manuales ingleses. Por el contrario, existe un gran número de páginas (cerca del $40-45 \%$ de todo el manual) dedicadas a la historia de la vida cotidiana, el género, las leyes de pobres, la conflictividad, el vestido, la vivienda, etc. Unas influencias muy claras de la historia desde abajo, la microhistoria, y las nuevas co-

\footnotetext{
${ }^{42}$ Marc Bloch, Apología para la historia o el oficio del historiador (México: FCE, 2001).
} 
rrientes historiográficas surgidas tras el postmodernismo. ${ }^{43}$ Hay muchos ejemplos de esta tendencia. Así, el manual de Collins para el primer curso del Key Stage 3 (year 7), a la hora de abordar el campesinado de la Edad Media lo hace a través de esta pregunta «¿Eran los campesinos medievales estúpidos?». A través de esa pregunta analizan el punto de vista del campesinado medieval, sus habilidades y su trabajo. Como contrapunto, el siguiente dossier comienza con otra pregunta " ¿Eran los habitantes de la ciudad más inteligentes que los campesinos?». Una clara manifestación de intenciones que permite abordar los procesos históricos desde la reflexión, y huyendo de los clichés y estereotipos. Igualmente interesante es el dossier del libro de Heinemann (History in progress) para el mismo curso cuando indaga en niños y jóvenes que tuvieron un importante impacto en la Edad Media. Es habitual en los manuales ingleses introducirse en biografías de personajes (no siempre personajes relacionados con el poder) para profundizar en temáticas políticas, sociales o culturales. También en el mismo libro (Heinemann) cuando aborda la naturaleza del poder en los siglos medievales lo hace a través de una pregunta «¿Quién tenía el poder: la Corona o la Iglesia?». Y esa pregunta la trabaja a través de varios dossiers como «muerte en la catedral», donde indaga sobre la muerte del Arzobispo de Caterbury (Thomas Becket) en 1170, como una manifestación de ese enfrentamiento Corona-Iglesia. Preguntas como «¿Por qué era la gente pobre en la época de los Tudor?» o «¿Cuáles fueron las consecuencias para las mujeres de la revolución industrial?» son el comienzo de interesantes temas abordados a través de páginas de dossiers específicos, de imágenes, de documentos de historiadores y textos de la época.

Sin duda el importante peso de la historia social en la historiografía inglesa influye en la presentación de estos temas. Hay una larga tradición del interés por la historia social que se remonta a la década de $1940 .{ }^{44} \mathrm{~A}$ partir de 1970 hubo un gran desarrollo de investigaciones vinculadas a esta perspectiva historiográfica. En este desarrollo participaron algunos historiadores relacionados con la escuela marxista, como Rodney Hilton $^{45}$ en el campo de la historia medieval y el estudio del campesinado;

\footnotetext{
${ }^{43}$ Peter Burke (coord.), Formas de hacer historia (Madrid: Alianza, 2003).

${ }^{44}$ G. D H. Cole, The common people, 1746-1946 (London, Routledge, 1938); G. M. Trevelyan, English Social History (London: Book Club Associates for Longman, 1944).

${ }^{45}$ Rodney Hilton, Conflicto de clases y crisis del feudalismo (Barcelona: Crítica, 1988).
} 
Christopher Hill ${ }^{46}$ y su trabajo en la Revolución Inglesa del siglo XVII; Eric Hobsbawm por la clase obrera, las revoluciones burguesas y su última preocupación por otros campos más vinculados a la nueva historia social, ${ }^{47}$ y Edward P. Thompson y sus contribuciones a la reflexión sobre la historia social, la revolución y la lucha de clases. ${ }^{48}$ Pero también hubo historiadores que impulsaron esta historia social influidos por otras tradiciones historiográficas más vinculadas a Max Weber, como Harold Perkin, ${ }^{49}$ primer profesor universitario en Inglaterra de Historia Social. Los grandes debates en el ámbito británico sobre la historia social y cultural ha puesto el acento en la gente corriente como motores de la historia. ${ }^{50}$ Y esto se ha reflejado de forma muy clara en los manuales. Lamentablemente los interesantes debates historiográficos en el ámbito hispano no ha tenido su transposición al ámbito de los libros de texto. ${ }^{51}$

\section{Eurocentrismo vs. anglocentrismo}

Al igual que ocurre con la influencia historiográfica, los contenidos y las representaciones sociales sobre temas nacionales y no nacionales son muy diferentes en los libros de texto ingleses con respecto a los españoles y franceses (gráficos 4, 5 y 6). Estos últimos tienen un marcado peso de eurocentrismo. Cerca del $40-50 \%$ de los temas propuestos por los manuales españoles y franceses provienen de temas europeos, incluso en ocasiones más que los propios temas nacionales. En el caso español, el hecho de que en $1 .^{\circ}$ de la ESO los temas que se imparten son de la Prehistoria y la Edad Antigua desvirtúa los resultados del gráfico 4. Estos temas se imparten en cursos anteriores en el caso inglés y francés, y por

\footnotetext{
${ }^{46}$ Christopher Hill, El mundo trastornado. El ideario popular extremista en la revolución inglesa del siglo XVI (Madrid: Siglo XXI, 1983).

${ }^{47}$ Eric Hobsbawm, Gente poco corriente. Rebelión, resistencia y jazz (Barcelona: Crítica, 1999).

${ }^{48}$ Edward P. Thompson, Tradición, revuelta y conciencia de clase. Estudios sobre la crisis de la sociedad preindustrial (Barcelona: Crítica, 1984).

${ }^{49}$ Harold Perkins, The Structured Crowd: Essays in English Social History (London: Harvester Books, 1981); Harold Perkins, The Making of a Social Historian (London: Athena Press, 2001).

${ }^{50}$ G. Iggers, Historiography in the Twentieth Century: From scientific objectivity to the postmodern challenge (Middletown: Wesleyan University Press, 2005); L. Kramer y S. Maza (eds), A Companion to Western Historical Thought (Oxford: Blackwell, 2006); J. Tosh, The pursuit of history (Harlow: Pearson Longman, 2010).

${ }^{51}$ Por poner un ejemplo: José Álvarez Junco (coord.), Las historias de España. Visiones del pasado y construcción de identidad (Madrid: Crítica-Marcial Pons, 2013).
} 
sus características (se centran principalmente en Egipto, Mesopotamia, Grecia o Roma) aparecen unos resultados diferentes. Sin embargo, si atendemos al gráfico 6 (donde se han recogido los temas de la Edad Media y la Edad Moderna hasta el siglo XVII), se perciben unos resultados muy parecidos en Francia y en España.

El caso inglés es muy distinto. Europa apenas aparece en los manuales antes del siglo XVIII, salvo pinceladas esporádicas. Prácticamente todos los temas son británicos, e incluso se trabaja con más profundidad realidades alejadas como la China imperial, que contenidos de Francia, España o Italia, por poner un ejemplo. Mientras que en los libros españoles se habla de la Guerra de los Cien Años, o en Francia se trabajan algunos de los contenidos de la «Reconquista», en los libros ingleses no aparecen temas de la Edad Media europeos que no estén directamente relacionados con su trayectoria institucional o política. Es curioso que en dos de los tres manuales analizados (Collins y Heinemann) no aparezca la colonización y conquista de América por parte de españoles y portugueses como un tema relevante.

Gráfico 4. Historia nacional /no nacional en los libros de texto de España, Francia e Inglaterra (primer curso de Educación Secundaria)

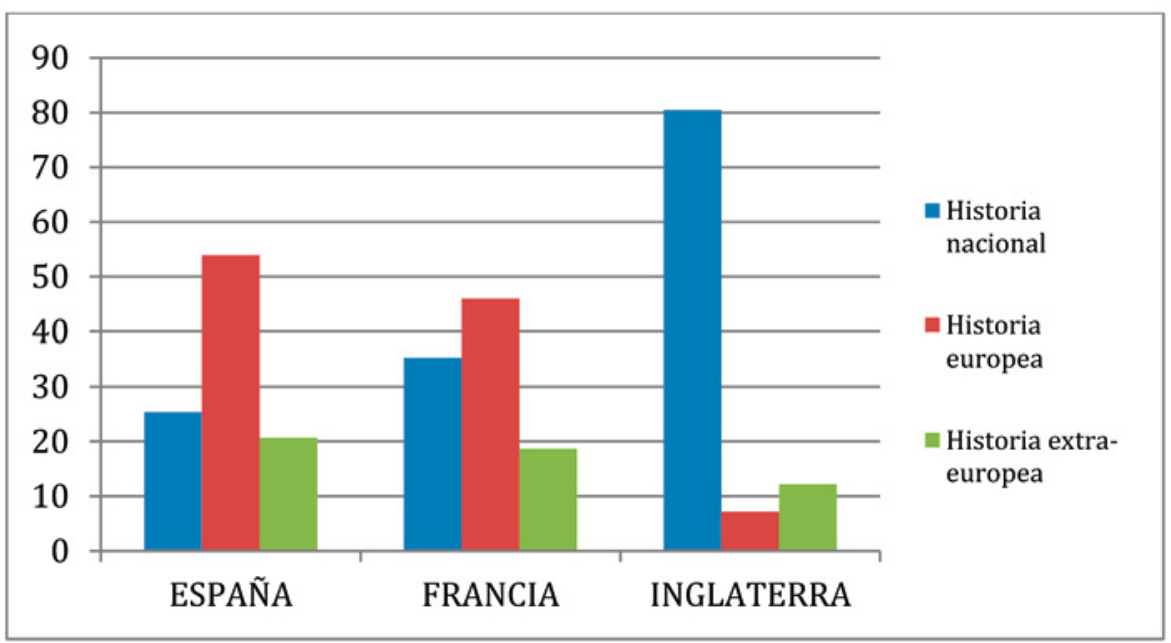


Gráfico 5. Historia nacional /no nacional en los libros de texto de España, Francia e Inglaterra (segundo curso de Educación Secundaria)

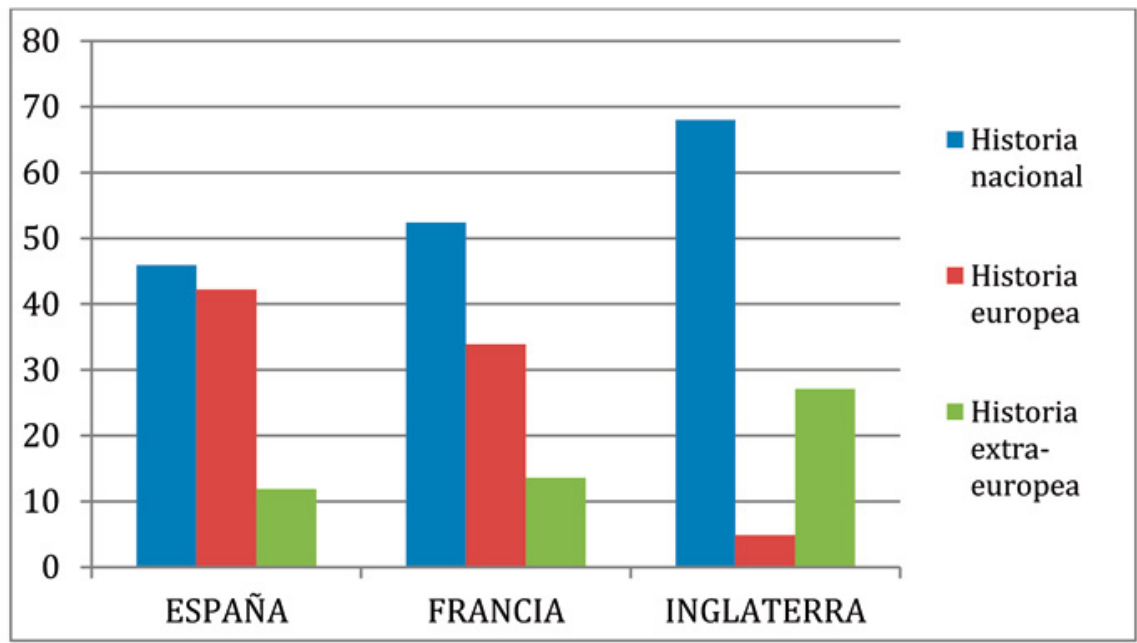

Gráfico 6. Historia nacional /no nacional en los libros de texto de España, Francia e Inglaterra (Edad Media y Edad Moderna)

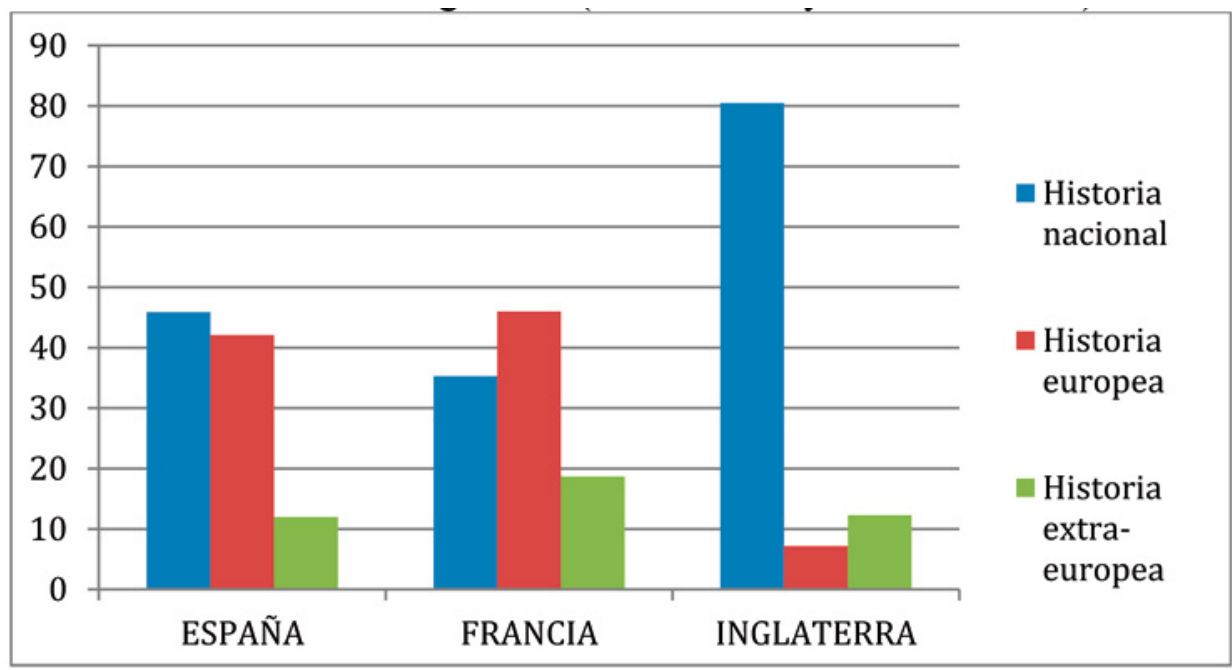

Esta forma de mostrar los contenidos históricos no sólo es consecuencia del anglocentrismo del currículum inglés. Los libros de texto ingleses además tienen una forma muy diferente de concebir el tiempo histórico. Los manuales franceses y españoles están muy influenciados por la co- 
rriente de Annales, y más concretamente por la propuesta de los tempos de la historia de Fernand Braudel en la segunda mitad del siglo Xx. ${ }^{52}$ Según este autor el tiempo cronológico — la sucesión de acontecimientos en el pasado- es sólo la «corteza» de la realidad social, una herramienta para situar hechos históricos, pero no es un fin en sí mismo. ${ }^{53}$ Braudel afirmaba que en todo análisis histórico podían observarse fenómenos de larga, media y corta duración. Estas tres dimensiones temporales (estructuras, coyunturas y acontecimientos) han sido la base de la narrativa presente en los manuales franceses y españoles.

Así, para abordar cualquier época histórica los libros de texto españoles y franceses proponen una estructura común: política, población, sociedad, economía, cultura y arte. Estos contenidos suelen enmarcarse en unas líneas de larga duración (grandes épocas históricas: Edad Media, Edad Moderna, etc.); en unas coyunturas basadas en un «tiempo medio» (periodos y coyunturas políticas y económicas de crecimiento y recesión o periodos culturales: Renacimiento, Barroco, etc.); y en un «tiempo corto" basado principalmente en la trayectoria de las instituciones de poder (acontecimientos políticos, batallas, guerras, etc.). El hecho de utilizar estas tres dimensiones temporales obliga a buscar una entidad supranacional en la que enmarcar esos procesos de larga duración. Cuando los manuales españoles y franceses explican sus coyunturas políticas, económicas o culturales, lo hacen en el contexto de procesos de larga duración europeos. Así, antes de adentrarse en temas nacionales, los libros de texto abordan temáticas como el feudalismo en Europa, la reafirmación del poder de las monarquías medievales frente a poder señorial, la construcción de las monarquías autoritarias, el absolutismo, el humanismo en Europa, o la revolución científica y sus consecuencias culturales y científicas. Estos temas son coincidentes en los manuales franceses y españoles, mostrando el devenir histórico nacional en un marco de construcción europea.

Los planos temporales que utilizan los libros de texto ingleses para encajar la narrativa histórica son muy diferentes. Sus propuestas tienen más relación con los diferentes planos del tiempo histórico: cronología,

\footnotetext{
52 Fernand Braudel y Armand Colin, «Histoire et sciences sociales: La longue durée», Réseaux, 5 (27), (1987): 7-37.

${ }^{53}$ Cristófol A. Trepat, «El tiempo en la didáctica de las ciencias sociales», en El tiempo y el espacio en la didáctica de las ciencias sociales, eds. C. A. Trepat y P. Comes (Barcelona: Graó, 2002), 7-22.
} 
duración, continuidad/cambio y simultaneidad. En palabras de Hernández Cardona, ${ }^{54}$ sea cual sea la organización de tiempo que se quiera hacer, la ubicación cronológica, la duración, los elementos de continuidad/cambio y los aspectos de simultaneidad, respecto a otros fenómenos, forman parte consustancial de cualquier contenido histórico de carácter factual o conceptual. Un determinado hecho o fenómeno histórico tiene que estar acotado en cuanto a su duración relativa. Así, los libros de texto ingleses se centran en preguntas e interrogantes clave que suelen girar en torno al poder (su naturaleza, origen y desarrollo), la sociedad y la vida cotidiana (formas de organización, conflicto, diferencias sociales, temáticas de género, etc.). Estas temáticas e interrogantes los centran sobre el caso inglés, intentando responder a esa definición de tiempo histórico (cronología, duración, cambio/continuidad y simultaneidad). No utilizan ninguna entidad supranacional que enmarque esos procesos históricos. Además, cuando plantean la dimensión temporal de simultaneidad lo hacen con otras realidades geográficas alejadas, como China, Sudáfrica o el reino de Mali.

En realidad, la gran diferencia en las representaciones sociales y en los contenidos históricos propuestos por los manuales españoles, franceses e ingleses está en la propia narrativa. La preocupación de los libros de texto españoles y franceses está en conjugar ese triple marco temporal (larga, media y corta duración), de forma que la narrativa nacional quede enmarcada en unos fenómenos coherentes con la construcción europea. Sin embargo, la finalidad de los manuales ingleses es responder esos interrogantes clave. Para ello no importa tanto seguir un guión temporal estructurado. De hecho, los cortes cronológicos no coinciden en ninguna de las tres editoriales estudiadas. La finalidad de la narrativa propuesta por los manuales ingleses está más relacionada con responder a esas preguntas clave desde diferentes planos temporales (cronología, duración, cambio/ continuidad, simultaneidad), y desarrollando en el alumnado conceptos de segundo orden y competencias históricas: trabajo con fuentes y evidencias, explicación causal, relevancia histórica, cambio y continuidad, y la argumentación histórica. No cabe duda de la influencia de autores como Ashby, Chapman, Cooper, Lee o Shelmit en esta propuesta. ${ }^{55}$

\footnotetext{
${ }^{54}$ Xavier Hernández Cardona, Didáctica de las Ciencias Sociales, geografía e historia (Barcelona: Graó, 2002).

${ }^{55}$ Rosalyn Ashby, «Developing a concept of historical evidence: Students' ideas about testing singular factual claims», International Journal of Historical Learning, Teaching and Research, 4 (2), (2004):
} 


\section{CONCLUSIONES}

Tras la comparación de las influencias historiográficas y los temas nacionales y no nacionales en los manuales, los resultados muestran unos datos muy interesantes sobre la construcción de identidades colectivas en cada uno de los territorios estudiados. La nación, como sujeto, sigue siendo primordial en los manuales de estos tres países. Sin embargo, las diferencias son significativas. El marcado peso del positivismo rankeano en los manuales españoles incide en una lectura lineal de la construcción de la nación, mientras que se dan rasgos estructurales - excesivamente estereotipados- de la sociedad y la economía. Estos dos temas ocupan una posición muy secundaria, y el abrumador peso de la historia política e institucional sólo se compensa con un mayor protagonismo de la historia del pensamiento y del arte desde una perspectiva macroestructural (Humanismo, Contrarreforma, la revolución científica, el Barroco, el Renacimiento, etc.). La presencia de la vida cotidiana es muy puntual y muy superficial, con arquetipos estereotipados. La sociedad tiene un peso secundario en el proceso de construcción de la nación, y el motor de la historia sigue siendo el acontecer de reinados y coyunturas políticas y artístico-culturales. Los contenidos históricos se transmiten habitualmente de forma descriptiva, enciclopédica y como un pensamiento ya construido. ${ }^{56} \mathrm{El}$ conocimiento se plantea de forma atomizada, estructural, y en un soporte más parecido a contenedores-estancos.

Los manuales franceses presentan una historia más viva, a pesar de que comparte algunos de los rasgos estructurales presentes en los libros de texto españoles. La presencia de temas culturales (la moda, el vestido, la vivienda, el género, la preocupación temprana por el patrimonio, etc.),

44-55; Arthur Chapman, «Taking the perspective of the other seriously? understanding historical argument», Educar em Revista, Curitiba, Brasil, 42, (2011): 95-106; Hilary Cooper y Arthur Chapman, Constructing History, 11-19 (Londres: Sage, 2009); Peter Lee, «Putting principles intro practice: understanding history», en How students learn: History in the classroom, eds. M. Donovan y J. Bransford (Whasington: National Academies Press, 2005), 31-77; Peter Lee y Rosalyn Ashby, «Progression in Historical Understanding among Students ages 7-14», en Knowing, Teaching and Learning History. National and International Perspectives, eds. P. N. Stearns, Peter Seixas y Sam Wineburg (Nueva York-Londres: New York University Press, 2000), 199-222; Peter Lee y Denis Shelmit, «I just wish we could go back in the past and find out what really happened: progression in understanding about historical accounts», Teaching History, 117, (2004): 25-31.

${ }^{56}$ Christian Laville, «Histoire et education civique constat d'echec, propos de remediation», en Pistes didactiques et chemins d'historiens. Textes offerts à Henri Moniot, eds. Marie-Christine Baquès, Annie Bruter y Nicole Tutiaux-Guillon (París: L’Harmattan, 2003), 225-240. 
y temas transversales (como las ciudades portuarias o el esclavismo) provoca que el relato escape de la linealidad de los manuales españoles. La nación sigue siendo el centro del discurso (principalmente en la Monarquía Absoluta con Luis XIV y en el germen, desarrollo y evolución de la Revolución Francesa). Pero el recurso a temas sociales de interés, los estudios de caso (Londres del siglo XVIII o el puerto de Nantes en el siglo XVIII), el uso continuo de fuentes primarias de la época (recursos textuales), textos de historiadores, y el análisis de imágenes de contenido histórico, supera la monotonía de los libros de texto españoles. El método del historiador tiene una mayor presencia en las páginas de los manuales franceses a través del análisis de fuentes de diferente procedencia (fuentes primarias, textos de historiadores e ilustraciones). Esto les acerca más a la filosofía de Annales, como se refleja en las palabras de Marc Bloch (2001):

Todo libro de historia digno de ese nombre debiera incluir un capítulo que se titularía más o menos: ¿Cómo puedo saber lo que voy a decir? Estoy persuadido de que, si se conociesen estas confesiones, hasta los lectores que no fueran del oficio hallarían en ellas un verdadero placer intelectual. El espectáculo de la investigación, con sus éxitos y fracasos, no es casi nunca aburrido. Lo acabado es lo que destila pesadez y tedio. ${ }^{57}$

Los manuales ingleses presentan una gran paradoja. Son quizás los manuales que más páginas le dedican a su nación, ignorando el resto de Europa. Sin embargo, al mismo tiempo, son los que más le dedican a la sociedad, alejándose de las imágenes arquetípicas y estereotipadas que aparecen en los libros de texto españoles y en parte de los franceses. Plantean interrogantes muy interesantes en torno a problemáticas históricas. Trabajan con textos de la época, textos de historiadores, y profundizan en las temáticas a través del oficio del historiador. Realizan estudios de caso para hacer reflexionar al alumnado sobre temáticas sociales, y además desde una perspectiva historiográfica más actualizada que los manuales españoles (y en gran parte más actualizada que los manuales franceses). Sin embargo, el relato que presenta de la construcción de la nación inglesa (sobre todo en los siglos de la Edad Media y Edad Moderna) es to-

\footnotetext{
${ }^{57}$ Bloch, Apología para la historia o el oficio del historiador.
} 
talmente anglocéntrica. Mientras que los manuales españoles y franceses plantean esa construcción nacional dentro de un marco europeo (del que se sienten partícipes), en Inglaterra sienten ese proceso como ajeno a su propio acontecer. No cabe duda la influencia de esta circunstancia en el sentimiento nacional y en la construcción de identidades colectivas.

\section{Nota sobre los autores:}

Cosme J. Gómez Carrasco es Profesor Contratado Doctor en la Facultad de Educación de la Universidad de Murcia. Con anterioridad ha sido becario predoctoral (FPI) en la Facultad de Humanidades de Albacete, becario postdoctoral en la École des Hautes Études en Sciences Sociales de París, e Investigador Postdoctoral en el Instituto de Historiografía «Julio Caro Baroja» de la Universidad Carlos III de Madrid. Además, ha sido investigador visitante en el European University Institute de Florencia (2006), Profesor Invitado en el Centre de Recherches Historiques (EHESS, París) en 2015 y Honorary Researcher Associate (Institute of Education, University College of London) en 2016. Es autor de más de un centenar de aportaciones científicas entre artículos, libros, capítulos, comunicaciones y ponencias en congresos nacionales e internacionales. Destacan sus publicaciones en revistas internacionales en Inglaterra (International Journal of Historical Learning. Teaching and Research), Italia (Popolazione e Storia), Francia (Spirale. Revue de Recherches en Education), Brasil (Tempo e Argumento), Chile (Revista Historia Social y de las Mentalidades), Colombia (Revista de Estudios Sociales), México (Perfiles Educativos y Revista Electrónica de Investigación Educativa) o Costa Rica (Revista Educare). Ha coordinado seis monografías sobre investigación, innovación y formación del profesorado en Educación Infantil, Primaria y Secundaria. Sus líneas de investigación actuales giran en torno al análisis comparativo internacional de libros de texto de historia; la evaluación del conocimiento histórico; el pensamiento histórico y narrativo e historiografía e historia social.

Arthur Chapman es Senior Lecturer en el Department of Curriculum, Pedagogy and Assessment del Institute of Education, University College of London. Enseñó historia en Educación Secundaria durante 12 años y es profesor en educación superior a tiempo completo desde 2005 en las universidades de Cumbria, Edge Hill y finalmente la UCL-Institute of Educa- 
tion. Es editor de las revistas Teaching History e International Journal of Historical Learning. Teaching and Research. Además, está en el comité editorial de las revistas London Review of Education y The Curriculum Journal. Destacan sus libros Constructing History, 7-11, editado junto a Hilary Cooper, y Join-Up History. New Directions in History Educational Research, editado con Arie Wilschut. Sus líneas de investigación giran en torno a la enseñanza y el aprendizaje de la historia en la enseñanza obligatoria, postobligatoria y superior. Sus intereses de investigación y consultoría incluyen el diseño curricular de historia, la enseñanza del Holocausto, las perspectivas internacionales sobre la enseñanza de la historia, el uso de tecnologías interactivas en la enseñanza de la historia y el desarrollo del pensamiento histórico.

\section{Referencias:}

Álvarez Junco, José, coord. Las historias de España. Visiones del pasado y construcción de identidad. Madrid: Crítica-Marcial Pons, 2013.

ApPlE, Michel W. Official Knowledge: Democratic Education in a Conservative Age. London: Routledge, 1993.

Apple, M. W., y L. K. Christian-Smith. «The Politics of theTextbook». In The Politics of the Textbook, edited by M. W. Apple and L. K. Christian-Smith, 1-21. New York: Routledge, 1991.

AsHBY, Rosalyn. «Developing a concept of historical evidence: Students' ideas about testing singular factual claims». International Journal of Historical Learning, Teaching and Research 4 (2) (2004): 44-55.

Aubin, P. «La pénétration des manuels scolaires de France au Québec. Un cas-type: Les frères des Écoles chrétiennes, XIXe-Xxe siècles». Histoire de l'Education 85 (2000): 3-24.

BAQuÈs, M. C. «L'évolution des manuels d'histoire du lycée. Des années 1960 aux manuels actuels». Histoire de l'Education 114 (2007): 121-149.

BARCA, Isabel. "La evaluación de los aprendizajes en historia». In La evaluación y el proceso de enseñanza y aprendizaje de las ciencias sociales, edited by $\mathrm{P}$. Miralles, S. Molina and A. Santisteban, 107-120. Murcia: AUPDCS, 2011.

— «Till new facts are discovered: Students'ideas about objectivity in history». In International review of history education, Vol. 4: Understanding history: Recent research in history education, edited by R. Ashby, P. Gordon and P. Lee, 68-82. New York: Routledge Falmer, 2005.

BARTON, Keith C. "Applied research: Educational research as a way of seeing». In The professional teaching of history: UK and Dutch perspectives, edited by 
A. McCully, G. Mills, and C. van Boxtel, 1-15. Coleraine, Northern Ireland: History Teacher Education Network, 2012.

Berr, A. En marge de l'histoire universelle. París: Albin Michel, 1953.

Blanco, A. «La representación del tiempo histórico en los libros de texto de primero y segundo de la Enseñanza Secundaria Obligatoria». Enseñanza de las Ciencias Sociales. Revista de investigación 7 (2008): 77-88.

BLoch, Marc. Apología para la historia o el oficio del historiador. México: FCE, 2001.

Braudel, Fernand y Armand Colin. «Histoire et sciences sociales: La longue durée». Réseaux 5 (27) (1987): 7-37.

Burke, Peter, coord. Formas de hacer historia. Madrid: Alianza, 2003.

CAJANI, L. "Italian history textbooks on the brink of the twenty-first century». In School history textbooks across cultures: International debates and perspectives, edited by J. Nicholls, 27-41Oxford: Symposium books, 2006.

CARretero, Mario, Alberto Rosa and M. ${ }^{a}$ Fernanda GonzÁLEz. «Enseñar historia en tiempos de memoria». In La enseñanza de la historia y memoria colectiva, edited by M. Carretero, A. Rosa and M. ${ }^{a}$ F. González, 11-36. Buenos Aires: Editorial Paidós, 2006.

Clark, Penney. "AA Nice Little Wife to Make Thing Pleasant”: Portrayal of Women in Canadian History textbooks approved in British Columbia». McGill Journal of Education 40 (2) (2005): 241-265.

Cole, G. D H. The common people, 1746-1946. London, Routledge, 1938.

Cooper, Hilary, and Arthur CHAPman. Constructing History, 11-19. Londres: Sage, 2009.

CuEnCA, José María, and Isabel López. «La enseñanza del patrimonio en los libros de texto de Ciencias Sociales, Geografía e Historia para ESO». Cultura y Educación 26 (1) (2014): 1-43.

CHAPMAN, Arthur. «Taking the perspective of the other seriously? understanding historical argument». Educar em Revista, Curitiba, Brasil 42 (2011): 95-106.

CHARTIER, Roger. Cultural History: Between Practices and Representations. Cornell: Cornell University Press, 1993.

- La historia o la lectura del tiempo. Madrid: Gedisa, 2007.

De CERTEAU, Michel. La escritura de la historia. México: Universidad Iberoamericana, 2010.

ElmersJö, H. A. «History beyond borders: Peace education, history textbooks revision, and the internacionalization of history teaching in the twentieth century». Historical Encounters. A journal of historical consciousness, historical cultures, and history education 1 (1) (2014): 62-74. 
Estivalèzes, M. «Teaching About Islam in the History Curriculum and in Textbooks in France». Journal of Educational Media, Memory, and Society 7 (3) (2011): 45-60.

FosTER, Stuart. «The struggle for American identity: Treatment of ethnic groups in United States history textbooks». History of Education 28 (1999): 251-279.

Foster, Stuart. «Dominant Tradition in International Textbooks Research and Revision». Educational Inquiry 2 (1) (2011): 5-20.

- «Re-thinking History Textbooks in a Globalized World». In History Education and the Construction of National Identities, edited by M. Carretero, M. Asensio and M. ${ }^{a}$ Rodríguez-Moneo, 49-62. Charlotte: IAP Publishing, 2012.

Foster, Stuart, y K. A. CraWford, eds., What Shall We Tell the Children? International Perspectives on School History Textbooks. Greenwich, CT: Information Age Publishing, 2006.

FukuoKA, K. «School History Textbooks and Historical Memories in Japan: A Study of Reception». International Journal of Politics, Culture and History 24 (2011): 83-103.

Giordano, G. Twentieth-century textbook wars: A history of advocacy and opposition. New York: Peter Lang, 2003.

Gómez, Cosme J. «Pensamiento histórico y contenidos disciplinares en los libros de texto. Un análisis exploratorio de la Edad Moderna en 2. ${ }^{\circ}$ de la ESO». Ensayos. Revista de la Facultad de Educación de Albacete 29 (1) (2014): 131-158.

Gómez Cosme, J., y Pedro Miralles. «Los contenidos de ciencias sociales y las capacidades cognitivas en los exámenes de tercer ciclo de Educación Primaria ¿Una evaluación en competencias?». Revista Complutense de Educación 24 (2013): 91-121.

Gómez, Cosme J., y Ana María LóPEz. «Las imágenes de los libros de texto y su función en la enseñanza de la historia. Diseño de un instrumento de análisis». Enseñanza de las Ciencias Sociales, Revista de Investigación 13 (2014): 17-29.

Gómez, Cosme J., y Pedro MIRALLES. «¿Pensar históricamente o memorizar el pasado? La evaluación de los contenidos históricos en la educación obligatoria en España». Revista de Estudios Sociales 52 (2015): 52-68. doi:10.7440/res52.2015.04.

Gómez, Cosme J., Jorge ORTUÑo y Sebastián MolinA. «Aprender a pensar históricamente. Retos para la historia en el siglo XXI». Tempo e Argumento 6 (11) (2014): 1-25.

Gómez, Cosme J., Ramón Cózar y Pedro Miralles. «La enseñanza de la historia y el análisis de libros de texto. Construcción de identidades y desarrollo de competencias». Ensayos. Revista de la Facultad de Educación de Albacete 29 (1) (2014): 1-25.

Hernández Cardona, Xavier. Didáctica de las Ciencias Sociales, geografía e historia. Barcelona: Graó, 2002.

Hilton, Rodney. Conflicto de clases y crisis del feudalismo. Barcelona: Crítica, 1988. 
HiLl, Christopher. El mundo trastornado. El ideario popular extremista en la revolución inglesa del siglo XVI. Madrid: Siglo XXI, 1983.

HobsBawm, Eric. Gente poco corriente. Rebelión, resistencia y jazz. Barcelona: Crítica, 1999.

IgGers, G. Historiography in the Twentieth Century: From scientific objectivity to the postmodern challenge. Middletown: Wesleyan University Press, 2005.

KeRLINGER, F. N. Investigación del comportamiento. Métodos de investigación en ciencias sociales. México: McGraw-Hill, 2002.

KIZEL, A. «The presentation of Germany in Israelí History Textbooks between 19482014». Journal of Educational Media, Memory and Society 7 (1) (2015): 94-115.

Kramer, L., y S. MAZA, ed. A Companion to Western Historical Thought. Oxford: Blackwell, 2006.

LAVILle, Christian. "Histoire et education civique constat d'echec, propos de remediation". In Pistes didactiques et chemins d'historiens. Textes offerts à Henri Moniot, edited by Marie-Christine Baquès, Annie Bruter and Nicole Tutiaux-Guillon, 225-240. París: L’Harmattan, 2003.

Le Goff, Jacques. Marchands et banquiers du Moyen Âge. Que sais-je?. Paris: PUF, 2001.

Le Goff, Jacques, Roger Chartier, y Jacques Revel. La nouvelle histoire. París: PUF, 1978.

LE Roy, E. Montaillou, village occitan de 1294 à 1324. París: Gallimard, 1975.

LEE, Peter. «Putting principles intro practice: understanding history». In How students learn: History in the classroom, edited by M. Donovan and J. Bransford, 31-77. Whasington: National Academies Press, 2005.

LEE, Peter, y Denis Shelmit. «I just wish we could go back in the past and find out what really happened: progression in understanding about historical accounts». Teaching History 117 (2004): 25-31.

LEE, Peter, y Rosalyn AsHBY. "Progression in Historical Understanding among Students ages 7-14». In Knowing, Teaching and Learning History. National and International Perspectives, edited by P. N. Stearns, Peter Seixas and Sam Wineburg, 199-222. Nueva York-Londres: New York University Press, 2000.

LÓPEZ FACAL, R. «Nacionalismos y europeísmos en los libros de texto: identificación e identidad nacional». Clío \& asociados: la historia enseñada 14 (2010): 9-33.

MARTínez, Nicolás. "El uso de los manuales escolares de historia de España. Análisis de resultados desde la propuesta de Shulman». Íber. Didáctica de las Ciencias Sociales, Geografía e Historia 70 (2012): 48-58.

Martínez, Nicolás, Rafael Valls y Francisco PinEdA. «El uso del libro de texto de Historia de España en Bachillerato: diez años de estudio, 1993-2003 y dos reformas (LGE-LOGSE)». Didáctica de las ciencias experimentales y sociales 23 (2009): 3-35. 
Miralles, Pedro. «Las tendencias historiográficas recientes y la enseñanza de la Historia en Bachillerato». Revista de historiografía 2 (2005): 158-166.

Nicholls, J. «Methods in School Textbooks Research». International Journal of Historical Learning. Teaching and Research 3 (1) (2003): 11-26.

PANiAgua, Javier. «Dejad a los políticos en la cuneta. La historia social busca su propio espacio». Íber. Didáctica de las Ciencias Sociales, Geografía e Historia 12 (1997): 25-36.

PARKES, Robert J., y Heather SHARP. «Nietzschean perspectives on representations of national history in Australian school textbooks: What should we do with Gallipoli?». Ensayos. Revista de la Facultad de Educación de Albacete 29 (1) (2014): 159-181.

Paxton, R. J. «A Deafening Silence: History Textbooks and the Students Who Read Them». Review of Educational Research 69 (3) (1999): 315-339.

PERKINS, Harold. The Making of a Social Historian. London: Athena Press, 2001.

- The Structured Crowd: Essays in English Social History. London: Harvester Books, 1981.

PINGEL, F. The European home: Representations of 20th century Europe in history textbooks. Strasbourg: Council of Europe, 2000.

- UNESCO guidebook on textbook research and textbook revision. Braunschweig: GEI/UNESCO, 2010.

Porat, D. "It's Not Written Here, but This is What Happened: Students" Cultural Comprehension of Textbook Narratives on the Israeli-Arab Conflict». American Educational Research Journal 41 (2004): 963-996.

PRATS, Joaquim. "Criterios para la elección del libro de texto de historia». Íber. Didáctica de las Ciencias Sociales, Geografía e Historia 70 (2012): 7-13.

- «Hacia una definición de la investigación en Didáctica de las Ciencias Sociales». Enseñanza de las Ciencias Sociales. Revista de investigación 1 (2002).

RuSSEN, Jörn. «El libro de texto ideal. Reflexiones en torno a los medios para guiar las clases de historia». Iber. Didáctica de las Ciencias Sociales, Geografía e Historia 12 (1997): 79-90.

SÁız, Jorge. "Actividades de libros de texto de Historia, competencias básicas y destrezas cognitivas, una difícil relación: análisis de manuales de $1 .^{\circ}$ y $2{ }^{\circ}$ de ESO». Revista Didáctica de las Ciencias Experimentales y Sociales 25 (2011): 37-64.

- «Alfabetización histórica y competencias básicas en libros de texto de historia y en aprendizaje de los estudiantes». Didáctica de las Ciencias Experimentales y Sociales 27 (2013): 43-66.

- «El tratamiento de las competencias básicas en los actuales libros de texto de historia en secundaria. Limitaciones y propuestas de mejora». Íber. Didáctica de las Ciencias Sociales, Geografía e Historia 74 (2013): 52-61. 
SÁIz, Jorge. «La Península Ibérica medieval y las identidades en los actuales libros de texto de historia de 2. ${ }^{\circ}$ ESO». Íber. Didáctica de las Ciencias Sociales, Geografía e Historia 70 (2012): 67-77.

SeIXAs, Peter, y Tom Morton. The Big Six Concept of Historical Thinking. Toronto: Nelson, 2013.

STÖBER, G. «From textbook comparison to common textbooks? Changing patterns in international textbook revision». In History education and post-conflict reconciliation: Reconsidering joint textbook projects, edited by K. V. Korostelina and S. Lässig, 26-51. New York: Routledge, 2013.

Thompson, Edward P. Tradición, revuelta y conciencia de clase. Estudios sobre la crisis de la sociedad preindustrial. Barcelona: Crítica, 1984.

TosH, J. The pursuit of history. Harlow: Pearson Longman, 2010.

TREPAT, Cristófol A. "El tiempo en la didáctica de las ciencias sociales». In El tiempo y el espacio en la didáctica de las ciencias sociales, edited by C. A. Trepat and P. Comes, 7-22. Barcelona: Graó, 2002.

Trevelyan, G. M. English Social History. London: Book Club Associates for Longman, 1944.

VALLS, Rafael. «La Guerra Civil española y la dictadura franquista: las dificultades del tratamiento escolar de un tema potencialmente conflictivo». Enseñanza de las Ciencias Sociales. Revista de investigación 6 (2007): 61-73.

- «Las imágenes en los manuales escolares españoles de Historia, ¿ilustraciones o documentos?». Íber. Didáctica de las Ciencias Sociales, Geografía e Historia 4 (1995).

- «Los estudios sobre manuales escolares de historia y sus nuevas perspectivas». Didáctica de las Ciencias Experimentales y Sociales 15 (2001): 23-36.

- «Sobre la elección y usos de las imágenes de los manuales escolares de historia: un ejemplo español (1900-1998)». Clio \& asociados. La historia enseñada 4 (1999): 77-100.

- La enseñanza de la Historia y textos escolares. Buenos Aires: Zorzal, 2008.

Wilschut, A. «History at the mercy of politicians and ideologies: Germany, England, and the Netherlands in the 19th and 20th centuries». Journal of Curriculum Studies 42 (5) (2011): 693-723.

Zachos, D., y A. Michailidou. "“Others” in Textbooks: The Case of Greek Sixth Grade's History Textbook». Theory in Action 7 (3): 1-25. doi:10.3798/tia.19370237.14016. 